\title{
Role of Complementary and Alternative Medicine in Treatment and Prevention of Obesity; Molecular Strategies to Recommended Acceptance
}

\author{
Atif Amin Baig ${ }^{1 *}$, Omar Mahmoud Al-Shajrawi ${ }^{1}$, Yasrul IAB ${ }^{1}$, Anam Mahmood ${ }^{2}$, Sarfaraz A $^{3}$, \\ Chandrika $\mathbf{M}^{4}$, Hassanain Al-Talib ${ }^{5}$ and Nordin Simbak ${ }^{2}$
}

${ }^{1}$ Faculty of Medicine, Universiti Sultan Zainal Abidin, Malaysia

${ }^{2}$ School of Health Sciences, University of Lahore, Pakistan

${ }^{3}$ KBCMA College of Veterinary and Animal Sciences, Pakistan

${ }^{4}$ Faculty of Medicine and Health Sciences, University Malaysia Sabah, Malaysia

${ }^{5}$ Faculty of Medicine, Universiti Teknologi MARA (UiTM), Malaysia

*Corresponding author: Atif Amin Baig, Faculty of Medicine, Universiti Sultan Zainal Abidin, Kuala Terengganu, Malaysia.

To Cite This Article: Atif Amin Baig. Role of Complementary and Alternative Medicine in Treatment and Prevention of Obesity; Molecular Strategies to Recommended Acceptance. Am J Biomed Sci \& Res. 2019 - 4(5). AJBSR.MS.ID.000826. DOI: 10.34297/AJBSR.2019.04.000826

Received: August 07, 2019 | Published: August 19, 2019

Keywords: Exercise Physiology; Long-distance Running; Transdisciplinary Quantum Physio-Philosophy

\section{Introduction}

The incidence of obesity is increasing at an alarming rate which has led to a surge the obesity-related morbidity in the world. It is now a most evident problem in world's population therefore, it needs to be addressed [1]. According to WHO, obesity is defined as BMI equals to or greater than $30 \mathrm{~kg} / \mathrm{m}^{2}$ which is the accumulation of fat in adipose tissue to such an extent that may be fatal [2]. Obesity is now replacing malnutrition, infectious and contagious diseases as the most vital contributor to ill health. The obesity-related health problem poses a burden on the health care system and lowers the quality of life of obese people. Particularly, it causes many chronic conditions like hypertension, cardiovascular diseases, diabetes type, kidney stones, respiratory issues, gout, arthritis, stroke, chronic fatigue sleep disorders and certain types of cancer such as breast and prostate cancer [2,3]. The epidemic of obesity is due to a sedentary lifestyle, minimal or no physical activity, intake of saturated fatty acid, high calories carbohydrates, carbonated drinks, and preserved food and sometimes genetic involvement is susceptible [4]. Without modifying lifestyles through culture and environment, it would be difficult to attain healthy life patterns. Improved patient health, quality of life and reduced cost of care of patients with obesity and other obesity-related health issues will not be recovered and resolved by clinical interventions alone [5-7].
Obesity or overweight is always perceived to be due to high levels of calories intake and low level of physical activity, therefore, low-calorie diet and enhance physical activity is presumed to be the foremost treatment for obesity. Although increased physical activity helps obese patients to combat various health problems or even lowers the risk of coronary artery diseases, hypertension, diabetes, and stroke. However, there are some other methods which help patients to fight obesity under restricted or nonrestricted diet patterns $[8,9]$. There is new literature for the chronic care model which integrates both clinical and community system to address chronic problems, for instance, the use of complementary and alternative medicine [10]. National Centre for Complementary and Alternative medicine elaborated the term Complementary and alternative medicine as "a collection of diverse medical and healthcare system, practices, and products which are not considered as a current health care system" [11]. Due to increased public awareness through mass media, advertisement, and internet, people nowadays, are more attractive towards the use of comparative and alternative treatment to reduce weight and to get rid of body fat. Social pressure regarding body weight/size and desire to look smart compels obese subjects to use complementary and alternative medicine and they are massively used due to their short term and early effects $[6,11]$. 
In recent years, CAM therapies are widely used in addition to conventional medical treatment and people thought that they are extremely effective. However, until now, there are inadequate researches regarding the effectiveness and efficacy of CAM therapies for reducing weight and most of the current literature have fundamental methodological problems, they have significant health benefits along with major health-related risk factors [6]. When it comes to reducing weight and becoming smart, there is a wide range of complementary medicines available in the form of herbal supplements, they have little effect. Moreover, they help to reduce weight and as soon as you left those medicines, you will gain more weight than ever before so, this is one of the serious and alarming side effects of using complementary medicine. Examples include the use of herbal products, dietary supplements and over the counter medicine for shedding weight, although they have adverse side effects significant effect can be achieved when used in combination with allopathic medicine $[12,13]$.

Furthermore, people are more inclined towards the ancient practices such as dry needling: acupuncture; visits to complementary clinicians like naturopaths, homeopaths, and chiropractors; and meditative and thoughtful practices such as Reiki, yoga, massage, and tai chi. They may have adverse effects and can cause physical injury as well. Therefore, there is the impetus for physician knowledge of CAM strengths versus drawbacks and collaborative integration of CAM in clinical practice of physicians so that maximum benefit could be achieved $[14,15]$. Although, it is one of the vital factors to teach and educate medical students at universities and hospitals about CAM; which can be assumed as a "bottom-up" approach for preparing the health care system for improved integration of CAM. However, "top-down" changes are required and suggested to enhance patient care and health [16]. The top-down approach proposes to better illustrate CAM's role in contemporary health care, modifications must originate from governing organizations and administrations in the form of clearer recommendations. There is no clear agreement with the medical community regarding the efficacy of CAM therapies [16,17]. There is a serious need to discuss at social and legislative levels to even include it as an integrated part of the curriculum in the medical syllabus and also as a complementary framework in medicinal and health sciences under specific clear outcomes.

It is very important to have approval and commandments for the use for Cams so that physician should recommend CAM in specific circumstances. This inconsistency advocates a lack of consistency in the consideration of therapeutic effects of CAM when publishing these guidelines and may feed underlying negative insights of the validity of CAM within the medical community [18-20]. In such cases where the efficacy of certain medications has proven scientifically should be recommended by the physician based recommended combination of CAM with traditional medicines. For instance, if a plant like Hoodia Gordonii, which is a member of the
Asclepiadaceae (the milkweed family), is associated with appetite inhibition and few scientific studies are conducted on chief features (bioactivity of its biological ingredients, clinical application, in vivo biopharmaceutics, and safety) of this anti-obesity plant. Obviously, this has brought about a considerable concern, as $\mathrm{H}$. gordonii is among the most popular organic anti-obesity products. In such cases, where the efficacy of certain medications has evidenced scientifically; should be recommended by physicians a recommended combination of CAM with traditional medicines [21].

Diet and deficiency of exercise are the old reasons for obesity, and in the last two decades, genetic factors are under research and identification to be involved in obesity [22]. Mutations happen in the genes by naturally or hereditary to have a role in the obesity syndromes' (e.g., Bardet-Biedl syndrome) for example, but there is no clear pathway explaining the role of the intact gene in causing obesity $[23,24]$. Studies in humans showed the role of specific mutations in intact genes in severe human obesity, for example, Hyperphagia and impaired T-cell-mediated immunity in both mice and humans beside infertility are examples of leptin deficiency hormone under mutations [24-26]. One of the products studied previously to be effective against obesity are green tea leaves derived from Camellia Sinensis has shown to have It has polyphenols (catechins) as main bioactive molecules. These bioactive molecules increase energy consumption, triggering the oxidation, and sympathetic nervous system of fat metabolism, and for the alternative pathway, results in high production of enzymes responsible for hepatic fat oxidation, appetite prevention, and reduced nutrient absorption [27].

Another dietary supplement produces from the dehydrated Garcinia Cambogia fruit rind, which has a hydroxycitric acid, used in southern India. G. Cambogia product manages the sense of satiety and appetite by it is the mechanism of ATP-dependent citrate lyase enzyme, which exchanges the citrate to acetyl-CoA and oxaloacetate [28]. Several previous studies showed the effect of green tea catechins (GTCs) and green tea on the gene and protein expression in obesity. Another study showed that the catechinrich diet increased the expression of the medium-chain acylCoA dehydrogenase (MCAD) and acyl-CoA oxidase (ACO), which decreasing the fat accumulation and enhancing hepatic $\beta$-oxidation activity $[29,30]$. On the other hand, also there are studies showing its role in lipogenesis, including fatty acid synthase (FASN), and adipogenesis, including CCAAT/enhancer-binding protein alpha (C) $\mathrm{EBP} \alpha$ ), liver X receptor alpha), and (LXR- $\alpha$ peroxisome proliferatoractivated receptor gamma (PPAR- $\gamma$ ) [29]. Use of Complementary and alternative therapies are progressively increasing because the general population perceived them to be active in helping to ease some of the health challenges associated with obesity. Patient's knowledge and involvement, personal attributes, health beliefs, attitude to CAM and medical history are principally accountable for the increased use of cam rather than socio-demographic factors 
and socio-economic status. CAM therapies for the obese people should be extensively investigated in well-controlled experimental research settings to deliver safety and effective data on treatments, as well as authenticated treatment options for those with obesityrelated morbidity [31-33].

Looking into the current scope of obesity and its high incidence in different populations, there is a need to specify the reported evidence for CAM therapies as per type of obesity and mechanisms involved in obesity. Role of inflammation and genes involved can play a vital role not only in metabolically stabilization of obese subjects but also at the same time to decrease their BMI to make them socially more stable and acceptable.

\section{References}

1. Seidell JC, Halberstadt J (2015) The global burden of obesity and the challenges of prevention. Ann Nutr Metab 66(2): 7-12.

2. (2000) The Asia-Pacific perspective: redefining obesity and its treatment. World Health Organization.

3. Srivastava G, Johnson ED, Earle RL, Kadambi N, Pazin DE, et al. (2018) Under-documentation of obesity by medical residents highlights challenges to effective obesity care. Obesity (Silver Spring) 26(8): 1277 1284 .

4. Dietz WH, Solomon LS, Pronk N, Ziegenhorn SK, Standish M, et al. (2015) An integrated framework for the prevention and treatment of obesity and its related chronic diseases. Health Aff 34(9): 1456-1463.

5. Gureje O, Nortje G, Makanjuola V, Oladeji BD, Seedat S, et al. (2015) The role of global traditional and complementary systems of medicine in the treatment of mental health disorders. The Lancet Psychiatry 2(2): 168177.

6. Sharpe PA, Blanck HM, Williams JE, Ainsworth BE, Conway JM (2007) Use of complementary and alternative medicine for weight control in the United States. J Altern Complement Med 13(2): 217-222.

7. Calle EE, Rodriguez C, Walker Thurmond K, Thun MJ (2003) Overweight, obesity, and mortality from cancer in a prospectively studied cohort of US adults. N Engl J Med 348(17): 1625-1638.

8. Marmot M, Atinmo T, Byers T, Chen J, Hirohata T, et al. (2007) Food, nutrition, physical activity, and the prevention of cancer: a global perspective.

9. Knowler WC, Barrett Connor E, Fowler SE, Hamman RF, Lachin JM, et al (2002) Reduction in the incidence of type 2 diabetes with lifestyle intervention or metformin. The New England journal of medicine 346(6): 393-403.

10. Sui Y, Zhao HL, Wong VCW, Brown N, Li XL, et al. (2012) A systematic review of the use of Chinese medicine and acupuncture for the treatment of obesity. Obes Rev 13(5): 409-430.

11. Eisenberg DM, Kaptchuk T, Post DE, Hrbek AL, O'Connor BB, et al, (2016) Establishing an integrative medicine program within an academic health center: essential considerations. Acad Med 91(9): 1223-1230.

12. Astell KJ, Mathai ML, Su XQ (2013) A review on botanical species and chemical compounds with appetite suppressing properties for body weight control. Plant Foods Hum Nutr 68(3): 213-221.

13. A Holifa, Ahmad Zubaidi A Latif, Nordin B Simbak, AB Atif (2017) Alpha-tocopherol administration in diabetics as preventive and therapeutic agents in oxidative stress. Current Trends in Biomedical Engineering and Biosciences, 5(5).

14. Patel SJ, Kemper, KJ, Kitzmiller JP (2017) Physician perspectives on education, training, and implementation of cmplementary and alternative medicine. Adv Med Educ Pract 8: 499-503.
15. Briggs JP, Killen J (2013) Perspectives on complementary and alternative medicine research. JAMA 310(7): 691-692.

16. MacKinnon TS, Banhidy NF, Tuite DR (2017) Changing physician perspectives on complementary and alternative medicine: the need for a top-down approach. Adv Med Educ Pract 8: 637-639.

17. Ernst E, Terry R (2009) NICE guidelines on complementary/alternative medicine: more consistency and rigor are needed. Br J Gen Pract 59(566): 695-695.

18. Ernst E, Terry R (2010) Assessments of complementary and alternative medicine: the clinical guidelines from NICE. Int J Clin Pract 64(10): 1350

19. Gaster B, Holroyd J (2000) St John's wort for depression: a systematic review. Arch Intern Med 160(2): 152-156.

20. Posadzki P, Watson LK, Alotaibi A, Ernst E (2013) Prevalence of use of complementary and alternative medicine (CAM) by patients/consumers in the UK: a systematic review of surveys. Clin Med 13(2): 126-131.

21. Vermaak I, Hamman JH, Viljoen AM (2011) Hoodia gordonii: an up-todate review of a commercially important anti-obesity plant. Planta Med 77(11): 1149-1160.

22. Montague CT, Farooqi IS, Whitehead JP, Soos MA, Rau H, et al. (1997) Congenital leptin deficiency is associated with severe early-onset obesity in humans. Nature 387(6636): 903-908.

23. Ilyas MN, AB A, Al Hatamleh MAI, Al Shajrawi OM, Ariff TM, et al. (2018) Rising Trends of Obesity in Malaysia; Role of Inflammation and Inflammatory Markers in Obesity Related Insulin Resistance: A Nuclear Factor Kappa B (Nfkb) Perspective. Current Trends in Biomolecular Engineering \& Biosciences 10: 4.

24. A Holifa, Ahmad Zubaidi A Latif, Nordin B Simbak, AB Atif (2017) Alpha-tocopherol administration in diabetics as preventive and therapeutic agents in oxidative stress. Current Trends in Biomedical Engineering and Biosciences 5(5).

25. Farooqi IS, Keogh JM, Yeo GS, Lank EJ, Cheetham T, et al. (2003) Clinical spectrum of obesity and mutations in the melanocortin 4 receptor gene. N Engl J Med 348(12): 1085-1095.

26. Muhammad IN, Saifullah K, Hasssan B, Yasrul I, Norizan AG, et al. (2018) Prevalence of Obesity in Malaysia: Perspectives in Terengganu towards Development of Malaysian Obesity DNA Bank. Asian Journal of Medicine and Biomedicine 2(1): 16-19.

27. Bora K, Sarkar D, Konwar K, Payeng B, Sood K, et al. (2018) Disentanglement of the secrets of aluminum in the acidophilic tea plant (Camellia sinensis L.) influenced by organic and inorganic amendments. Food Res Int 120: 851-864.

28. Esteghamati A, Mazaheri T, Rad MV, Noshad S (2015) Complementary and alternative medicine for the treatment of obesity: a critical review. Int J Endocrinol Metab 13(2): e19678.

29. Semwal RB, Semwal DK, Vermaak I, Viljoen A (2015) A comprehensive scientific overview of Garcinia cambogia. Fitoterapia 102: 134-148.

30. Mohd Adzim Khalili Rohin, NorhayatiAbd Hadi, Rochman Naim, Atif Amin Baig, Khairil Mahmud (2014) Study on Antioxidant Capacity and Anticancer Activity of Bismillah Leaf (vernoniaamygdalina).World Journal of Pharmaceutical Research 3(6):14-29.

31. Hopf KP, Madren E, Santianni KA (2016) Use and perceived the effectiveness of complementary and alternative medicine to treat and manage the symptoms of autism in children: a survey of parents in a community population. J Altern Complement Med 22(1): 25-32.

32. Landor M, Benami A, Segev N, Loberant B (2015) Efficacy and acceptance of a commercial Hoodia parviflora product for support of appetite and weight control in a consumer trial. J Med Food 18(2): 250-258.

33. Atif AB (2018) Obesity Leads to Elevated Level of Circulating Cell-Free DNA. Current Trends in Biomolecular Engineering \& Biosciences 16(4). 